\title{
El nacionalismo musical mexicano una mirada desde la teoría del campo de Bourdieu
}

M.H Fernando de Jesús Serrano Arias

fernando.serrano@unison.mx

Dr. Leonel De Gunther Delgado

Universidad de Sonora

\section{Introducción}

Este trabajo problematiza la delimitación del período del nacionalismo musical mexicano planteada desde una postura historicista propia de la musicología. Esta última pone al frente el inicio y fin a partir de una obra, institución o autor como punto de partida, nuestro interés es confrontarla con la teoría del campo de Bourdieu. Se busca poner en relación las fuerzas de poder al interior del campo para señalar la situación de tensión que se percibe dentro del mismo, así como la posibilidad de la inclusión/exclusión del campo por el capital simbólico, cultural, social de sus agentes a partir de la estructura del campo, es decir, a partir de "la distancia entre las fuerzas específicas que se enfrentan en él" (Bordieu, 2011) definiendo el capital específico.

Para delimitar un campo es necesario conocer con claridad la estructura que lo conforma por lo que se deben establecer las fuerzas que trabajan al interior y el capital con el que cuentan. En este caso: ¿cuáles son las fronteras del campo "nacionalismo musical mexicano"?

Para una mejor comprensión de esto es necesario incorporar no sólo elementos musicales sino aquellos otros que van más allá, pero que inciden en lo musical. De ahí la importancia de un enfoque que incorpore elementos integradores tanto musicales como extra musicales.

A partir de lo anterior se incorpora la teoría del campo a la musicología como herramienta que aporta una visión más amplia de un fenómeno que impactó no sólo el terreno musical sino, la vida y la conformación de un imaginario sociocultural en México.

\section{El campo}

Para Bourdieu, un campo es "una trama de relaciones objetivas entre posiciones" (Bourdieu, 2013) las cuales se definen objetivamente en su existencia y en las determinaciones que imponen a sus ocupantes, ya sean agentes o instituciones, por su situación (situs) actual y potencial en la estructura de la distribución de las diferentes especies de poder (o de capital) - cuya posesión implica el acceso a las ganancias específicas que están en juego dentro del campo- y, de paso, por sus relaciones objetivas con las demás posiciones (dominación, subordinación, homología, etc.)" (Bourdieu y Wacquant, 2013, p. 150). Es decir, las relaciones solo adquieren significado dentro de un sistema de relaciones (Bourdieu, 2005). Esto permite plantearnos lo siguiente: tratar de determinar los límites del nacionalismo musical mexicano a partir de los límites que se dan dentro del campo mismo' con- 
siderando, por una parte, "las relaciones de fuerza entre los jugadores" (Bordieu, 2013) y por otra, reconociendo las especies de capital que actúan dentro del campo (cultural, simbólica, social, entre otras) y en qué límites ejercen sus efectos. Partiendo de esta concepción y para el análisis de los datos se utilizará la teoría de los campos de Pierre Bordieu. Se propone un análisis de correspondencia que implica el análisis de los datos a partir de las relaciones objetivas. Para esto, Bourdieu expone tres aspectos: (1) Analizar la relación de dominio entre el campo y el campo de poder. (2) Establecer las posiciones que ocupan los agentes y las instituciones que están en competencia dentro del campo para establecer la estructura objetiva de esas relaciones y (3) analizar los sistemas de disposiciones y los habitus que los agentes han adquirido a través de la interiorización de condiciones sociales y económicas determinadas.

Cada uno de los agentes del campo cuentan con un capital específico cuyo valor está en relación con el campo mismo. Fuera de él, es irrelevante. No obstante, al interior, ese capital le permite tener una posición de poder ya sea para poder "jugar" o bien, para influir en él y, las relaciones de fuerzas entre los "jugadores" es lo que establece la estructura del campo. Así, el poder que ejerza cada jugador está en función de la cantidad y estructura del capital en un momento específico y de la evolución en el tiempo. Cada jugador busca mejorar o por lo menos conservar su capital ya sea para transformar las reglas del juego o modificar el valor de cierto capital. Este choque de fuerzas hace que los límites del campo no sean claros. No obstante, como el mismo Bourdieu señala "los límites del campo están donde los efectos del campo cesan" (2009: 154). ¿Podemos pensar que el campo se establece no sólo por los que participan directamente, sino, por aquellos que es- tán excluidos y el porqué lo están? Sin embargo, para el analista, son las fuerzas activas las que se deben seleccionar para su estudio ya que son las que definen el capital específico.

Para construir el campo se debe reconocer la lógica específica que permitirá identificar las formas de capital específico que ahí operan, es decir, identificar "las propiedades activas que legitiman la participación o pertenencia, de un individuo, a un campo" (Bourdieu; 2009: 163). Luego entonces, si la fuerza de los agentes determina su posición en la estructura del campo, ¿cuál es la fuerza que posee un compositor al que la máxima autoridad educativa -Carlos Chávezí- le encarga una obra de caracter nacional contra otro que hubo de autoexiliarse por razones políticas -Manuel M. Ponce ${ }^{2}-$ ?

¿Como se configura un campo que atiende sólo a los agentes, sólo a las instituciones o sólo a los productos? O bien, si las tensiones entre las relaciones del campo de poder y del campo intelectual generan 1 Carlos Chávez (1889-1978) es considerado el creador del nacionalismo musical mexicano como movimiento postrevolucionario. Fue una figura prominente de la música en México. Compositor y director musical fue, además, director del Conservatorio Nacional, de la Sección de Bellas Artes de la Secretaría de Educación Pública y fundador y primer director del Instituto Nacional de Bellas Artes. Durante 21 años dirigió la Orquesta Sinfónica de México programando, entre otras, mucha obra mexicana. Cabe mencionar que el trabajo de la orquesta llevó a la audiencia mexicana a otro nivel en cuanto al repertorio escuchado en México hasta ese momento.

2 Manuel M. Ponce (1882-1948) pianista y compositor mexicano con una amplia trayectoria en la composición capaz de abordar diferentes estilos. Se le considera padre del estilo "mexicanista" que recoge la música tradicional y la viste de un ropaje más elegante. 
revoluciones artísticas, ¿qué pasa en México durante este período cuando el campo de poder absorbe al campo intelectual?

$\mathrm{Si}$ abordamos a un agente en particular (Ponce, Chávez, Revueltas, la Sinfónica de México, el Instituto Nacional de Bellas Artes) ¿podemos definir claramente los límites de eso que llamamos campo del nacionalismo musical mexicano? $\mathrm{O}, ¿$ debemos abordar a los diferentes agentes? Y aquí, podemos incluir a los que Saavedra (2010) enuncia como "compositores contemporáneos de Ponce hoy considerados menores ... Juan León Mariscal, José Pomar, Carlos Barajas y Antonio Gómezanda, por ejemplo" (p. 177), que, desde la historiografía nacionalista han quedado olvidados, o al menos, relegados, excluidos del campo.

Con la finalidad de delimitar el campo del nacionalismo musical mexicano es necesario conocer con claridad la estructura que lo conforma por lo que se deben establecer las fuerzas que trabajan al interior y el capital con el que cuentan. Es decir: ¿cuáles son las fronteras del campo "nacionalismo musical mexicano"?

Para tener una mayor comprensión de este campo es necesario incorporar no sólo los elementos musicales, sino otro conjunto de elementos que van más allá de estos. De aquí la importancia de una visión que incorpore elementos integradores para una mayor comprensión. Como señala De Gunther (2015) para comprender cómo opera y se constituye un campo, es necesario estudiar sus tres dimensiones: formal, social y política. En este caso hablamos de la dimensión social.

\section{El nacionalismo musical mexicano}

El campo de conocimiento de las artes en México tiene un sub-campo que surge en la primera mitad del siglo $\mathrm{XX}$ al cual denominamos nacionalismo mexicano. Este campo se constituye, sin duda, en la postura oficial, institucionalizada, de una serie de elementos artísticos emanados de la propuesta de José Vasconcelos (18821959), responsable de educación en México, y que abarcó a las distintas artes.

En la bibliografía musical mexicana no parece haber un consenso sobre la delimitación del período nacionalista. Moreno Rivas (1990) señala el año de 1921 como inicio, a partir de la composición del ballet El fuego nuevo de Carlos Chávez (1889-1978), que le encarga el mismo Vasconcelos. A decir de ella misma, inicia su descenso hacia fines de 1940. Por otro lado, Alcaraz (1998), pone a 1928 como fecha de inicio a partir de la fundación de la Orquesta Sinfónica de México; la fecha límite, es el año de muerte de José Pablo Moncayo, 1958. Ambos autores señalan a Chávez como el forjador de esa corriente musical.

Robles Cahero (2000) escribe que la música mexicana escrita entre 1910 y 1960 es “ecléctica y diversa". Señala que: "El nacionalismo musical mexicano fue proclive a la mezcla estilística, lo que explica el surgimiento de dos fases nacionalistas y varios estilos híbridos" (p. 40).

En pleno auge del período nacionalista, el musicólogo catalán formado en Alemania, Otto Mayer-Serra describe en su Panorama de la música en México, a Manuel M. Ponce como el forjador de este estilo nacional (1941) a partir del concierto que dio en 1912 con música propia y en la que incluyó piezas para piano basadas en melodías populares. Para Mayer-Serra esto significó una nueva fase en la historia de la música mexicana. Además, menciona que:

\footnotetext{
"a una distancia histórica de un cuarto de siglo logramos darnos cuenta de lo que significó para México la nueva orientación de Manuel M. Ponce (1882-1948), a la cual se adhirieron todos los compositores, que, hasta entonces, habían escrito casi exclusivamente música de carácter europeo" (1941: p. 153).
} 
Para el musicólogo es Ponce y no Chávez quien primero incursiona en el nacionalismo sinfónico con su obra Chapultepec también compuesta en 1921. Para Ponce, como señala Saavedra (2010), el punto de partida del nacionalismo musical mexicano fueron las actividades para la celebración del Centenario de la Independencia de septiembre de 1910, organizado por el gobierno de Porfirio Díaz. En una nota al pie señala que "las raíces del movimiento nacionalista de los años $\mathbf{1 9 2 0 - 1 9 4 0}$ es una fase de "masas" de un nacionalismo iniciado en el porfiriato" (Saavedra, 2010, p. 157).

Como se señaló en un principio, otro de los actores del campo fue el compositor Silvestre Revueltas ${ }^{4}$. En el libro Diálogo de resplandores: Carlos Chávez y Silvestre Revueltas (2002) Contreras Soto hace hincapié en que, aunque cada vez hay más personas que consideran a Revueltas como un compositor con una clara idea de lo que componía, sigue habiendo quien mantiene el imaginario de un compositor puramente intuitivo. Lo interesante es que en este mismo texto encontramos las dos posturas. Hay quien menciona que no compuso sinfonías no por que no pudiera, sino porque no quiso y quien señala que es un autor intuitivo. Es decir, si la capacidad para la escritura de sinfonías es un elemento para definir un aspecto del juego en la composición del campo, no queda claro si Revueltas es parte de él o no

Por otra parte, Saavedra (2002) en su artículo sobre Chávez, pone el dedo en la llaga al señalar que "Sus obras nacionalistas [de Chávez] datan del mismo período que sus obras abstractas y abiertamente no nacionalistas; éstas están construidas a partir de los mismos recursos composiciona-

3 El resaltado es de quien esto escribe. 4 Silvestre Revueltas (1899-1940) fue violinista y compositor que imprimió en su obra musical un sentido de "lo mexicano" sin recurrir a citas de otras músicas de México. les que las primeras". Y Parker (2009) en Trece panoramas en torno a Chávez, que abarca diferentes artículos escritos por él en diferentes períodos, habla del "indigenismo", el "mexicanismo" o el "nacionalismo" de Chávez.

Todo lo anterior nos permite suponer que no hay un consenso acerca de los límites del nacionalismo ni claridad sobre la fuerza de sus agentes.

Carredano (2017) describe, en términos no bourdeanos, los forcejeos al interior del campo: "Las pugnas por el liderazgo en la música mexicana producirían alianzas y reacomodos constantes: determinar la orientación estilística del nacionalismo y ocupar los espacios de influencia en las instituciones se convirtió en una aspiración generalizada por las distintas facciones" (p. 36).

Este campo que denominamos nacionalismo musical mexicano se configura tanto por sus agentes: Manuel M. Ponce, Carlos Chávez, Silvestre Revueltas, José Pablo Moncayo ${ }^{5}$, entre otros; así como por sus instituciones: Secretaría de Educación Pública, Conservatorio Nacional, Orquesta Sinfónica de México, entre otras.

A decir del mismo Chávez (1946) el "nacionalismo musical mexicano del XIX no produjo grandes obras, porque no hubo grandes compositores" (p. 533). Es decir, hay una negación por la herencia que está representada por los músicos mexicanos activos durante la formación de Ponce quien, formado en el romanticismo musical mexicano y en la vanguardia francesa, enlaza la tradición decimonónica con la postura nacionalista que se gesta en Europa. Sin embargo, finalmente, no es el nacionalismo de Ponce sino el de Chávez el

5 José Pablo Moncayo (1912-1958) fue compositor y alumno de Chávez quien, junto a otros tres estudiantes, formaron el grupo de los cuatro. Es autor de la obra Huapango (1941) que ha sido considerado como un segundo himno nacional. 
que se establece de manera institucional. Durante un periodo aproximado de cuarenta años, esa música oficial se programó en salas de concierto, se llevó al extranjero y se premió en diversos concursos. Desde la historia oficial y a la distancia, pudiera parecer que en ese lapso sólo se escribió música nacionalista entendida como "una doctrina que establece la necesidad, o la conveniencia, o la recomendación, de que las melodías y ritmos de la música popular se aprovechen en las composiciones de formas musicales superiores, como medio de lograr el establecimiento de un gran arte musical nacional" (Chávez, 1946, p. 533). Por su parte, Miranda (2015) establece que es la conjunción de tres generaciones de compositores (que parte de Ponce y concluye con el llamado "grupo de los cuatro": José Pablo Moncayo, Blas Galindo, Daniel Ayala y Salvador Contreras), así como "el deseo de crear -específicamente- repertorio mexicano" (p. 47), lo que lleva al florecimiento de una "intensa vida musical". No obstante, se presentan en este escenario otros agentes. Tal es el caso de Julián Carrillo quien considera que no hay en México una música nacional y se propone como el verdadero creador de una música mexicana desde su Sonido $13 .{ }^{6}$ O bien, como señala Julio Estrada (2012) sobre la importancia de Revueltas quien "pasa del indigenismo y se inclina por un universo popular que capta con el estilo franco de un mexicanismo mestizo y festivo" (p. 30).

\section{Consideraciones finales}

El propósito del texto es presentar una propuesta de investigación con la finalidad de aportar conocimiento al ámbito

6 Postura microtonal que aborda un nuevo universo sonoro mediante sonidos más allá de la escala de 12 tonos y para el que no sólo compuso música, sino que también fabricó instrumentos. musical, en particular a la noción de nacionalismo.

Se considera la incorporación de la teoría del campo de Bourdieu al terreno de la musicología como una herramienta para la comprensión de este período. Es importante señalar que esta herramienta -teoría del campo- tiene limitaciones que no permiten abordar la complejidad del tema musical por lo que es necesario incluir herramientas tradicionales de la musicología para completar la información, de ahí la necesidad de integrar saberes para intentar una comprensión, sino última, sí, al menos, mayor.

¿Cómo considerar nacionalista toda la obra de Chávez o Revueltas o Ponce que se ubique, cronológicamente, dentro de lo que se ha construido como período Nacionalista mexicano? ¿Son las obras de estos tres autores iguales en cuanto a su presentación mexicanista? ¿Utilizan todos elementos indígenas en todas sus obras dentro de este marco de referencia temporal?

Es decir, debemos de establecer cuáles son los elementos que definen el campo, cuáles son los actores preponderantes, los elementos de inclusión y/o exclusión para establecer los límites del nacionalismo musical mexicano.

La musicología, una disciplina que aprovecha otras disciplinas para un mayor conocimiento de la música, puede sacar provecho del análisis de correspondencia de Bourdieu para clarificar, a través de la teoría del campo, clasificaciones dentro de la cronología histórica en la historiografía musical mexicana. Es por todo esto que, se considera que la teoría de Bourdieu, como un elemento de análisis aunado a los tradicionales de la música, permitirá arrojar otra mirada para una mayor comprensión del periodo nacionalista musical de México. 


\section{Bibliografía}

Alcaráz, J. A. (1998). En la más honda música de la selva. México: CONACULTA.

Agamben, G. (1 de Marzo de 1998). ¿Qué es un campo? (F. Costa, Trans.) Buenos Aires, Buenos Aires, Argentina.

Bordieu, P. (2011). Las reglas del arte. Génesis y estructura del campo literario. (T. Krauf, Trans.) Buenos Aires, Argentina: Anagrama.

- (23 de junio de 2013). La lógica de los campos. Recuperado de internet el 23 de mayo de 2016 de Ssociólogos | Blog de Actualidad y Sociología: http://ssociologos.com/2013/06/23/entrevista-a-pierre-bourdieu-la-logica-de-los-campos-habitus-y-capital/

------- (1990). Algunas propiedades de los campos. En Bourdieu, P. Sociología y Cultura (pp. 135-141). México.

Chávez, C. (1946). La música. En S/A, México y la cultura (p. 625). México: Secretaría de Educación Pública.

Carredano, C. (2017). La crítica musical en México: Carlos Chávez y los músicos del exilio español. En Carredano, C. y Villanueva Carlos. (2017). Manuel de Falla en el imaginario de dos músicos exiliados: Adolfo Salazar y Jesús Bal y Gay. México. El Colegio de México.

De Gunther, L. (2015). Aportes para el abordaje del campo de conocimiento de las artes de la Universidad de Sonora: las dimensiones formal, social y política de su constitución. En C. Hurtado, R. Lozano, L. De Gunther, \& U. Mazariegos, Una visión interdisciplinaria del arte (1a ed., pp. 44-62). México: universidad de Sonora.

Estrada, J. (2012). Canto roto. Silvestre Revueltas. México: FCE, UNAM.

Fernández Fernández, J.M. (2009). La noción de campo en Kurt Lewin y Pierre Bourdieu: un análisis comparativo. En Revista Española de Investigaciones Sociológicas (Reis). Núm. 127, pp. 33-53

Gómez, A. (2013). La canción mexicana: sonido, poética e identidad. En Miranda, R. \& TeIlo, A. La música en los siglos XIX y XX (Vol. IV). México: CONACULTA. Págs. 169-194.

Mayer-Serra, O. (1941). Panorama de la Música Mexicana. D.F., México: El Colegio de México.

Miranda, R. \& Tello, A. (2013). La música en los siglos XIX y XX (Vol. IV). México: CONACULTA.

Miranda, R. (2015). "The heartbeat of an intense life:" Mexican Music and Carlos Chávez's Orquesta Sinfónica de México, 1928-1948. En Saavedra, L (Ed.). Carlos Chavez and his world. Londres: Princeton University Press. Págs. 46-61.

Moreno Rivas, Y. (1990). Historia mínima de la música clásica mexicana. México, D.F.: Patria.

Parker, R. (2009). Trece panoramas en torno a Chávez. México, D.F. CONACULTA.

Robles Cahero, J. A. (2000). La música mexicana de concierto en el siglo XX, eclecticismo y diversidad. En México en el tiempo (38), 38-45.

Saavedra, L. (enero-junio 2010). Manuel M. Ponce y la canción mexicana. En Heterofonía, revista de investigación musical; núm. 42. Págs. 155-182

------ (2002). Carlos Chávez y la construcción de una alteridad estratégica. En Bitrán, Y. y Miranda, R. Diálogo de resplandores: Carlos Chávez y Silvestre Revueltas. MéxiCo, D.F. CONACULTA. Págs. 125-138

Tello, A. (2013). Rasgos nacionales en la música mexicana de concierto del siglo XX. En Miranda, R. y Tello, A. La música en los siglos XIX y XX (Vol. IV, pp. 494-572). México: CONACULTA.

Vilar, L. (2002). Innovación, espontaneidad y coherencia armónica en Silvestre Revueltas. En Bitrán, Y. y Miranda, R. Diálogo de resplandores: Carlos Chávez y Silvestre Revueltas. México, D.F. CONACULTA. Págs. 31-46. 